\title{
OMAE2021-62516
}

\section{ON LIFETIME EXTENSION OF WIND TURBINE DRIVETRAINS}

\author{
Kelly Tartt ${ }^{1,2 *}$, Amir R. Nejad ${ }^{2}$, Abbas Kazemi-Amiri ${ }^{1}$, Alasdair McDonald ${ }^{3}$ \\ ${ }^{1}$ Department of Electronic and Electrical Engineering, University of Strathclyde, Glasgow, G1 1XQ, U.K. \\ ${ }^{2}$ Marine Technology Department, Norwegian University of Science and Technology, NO-7491, Trondheim, Norway \\ ${ }^{3}$ School of Engineering, University of Edinburgh, Edinburgh, EH9 3FB, U.K. \\ Email: kelly.tartt@strath.ac.uk
}

\begin{abstract}
The focused shift to reduce carbon emissions by substituting fossil fuels with renewable energy sources, including wind, is increasing. This means that more and more wind turbines are being installed, both onshore and offshore and as this number increases, more and more turbines are reaching their end of designed service life. Extending this designed service life, which is commonly referred to as lifetime extension (LTE), is particularly favoured by owner/operators, due to economic reasons. Whilst there are relatively well-established practices for lifetime extension of structural members or those preserving structural integrity, the electro-mechanical and drivetrain systems are often overlooked. Therefore, this paper reviews lifetime extension assessment practices executed within a variety of industries, such as oil and gas, marine vessels, electrical machines, mechanical rotating equipment and bearings, to determine if any of these practices can be implemented or adapted within the wind industry, particularly on wind turbine drivetrains.
\end{abstract}

\section{I: INTRODUCTION}

WindEurope [1] states that $15.4 \mathrm{GW}$ of new wind power capacity was installed in Europe in 2019. As the number of onshore and offshore wind farms increase, more and more turbines are reaching their end of designed service life, which is typically 20 years. Once a turbine reaches the end of its designed service life, there are three options that can be considered by the operator. The first being decommissioning, the second being re-powering

*Address all correspondence to this author. and the third being lifetime extension (LTE). Decommissioning involves dismantling the complete turbine and returning the site back to its original condition. Re-powering involves either replacing or modifying certain components to either improve or maintain the power output. LTE involves analysing the system to determine if the system can continue to operate in a safe manner.

It is of great interest for operators to keep the turbines in operation beyond their service life, with minimum or no additional expense, provided they meet both technical and safe operational requirements. Therefore, out of the three options described above, LTE is probably the most favoured option for operators due to economic factors.

At a very high level, a wind turbine can be broken down into three main groups, which are the support structure (tower and substructure), rotor/blades and nacelle. A vast amount of research has been carried out on LTE of the structural members of the wind turbine, such as the tower and blades but to date not a lot has been done on the drivetrain as a whole, which is located in the nacelle.

The drivetrain is the heart of the turbine, as it is where mechanical energy is converted into electrical energy. Typically a geared drivetrain system consists of shafts, gearbox, bearings, generator and converter, supported by a bedplate, and failure of any of these major components can have serious consequences to the supply of power, incurring large costs for the operator. Another reason why it is important to investigate the drivetrain is because the failure mechanism and damage rate of these components differ from structural members. For electro-mechanical components the time frame between initiation of the damage and

Copyright (C) 2021 by ASME

This is a peer-reviewed, accepted author manuscript of the following article: Tartt, K., R. Nejad, A., Kazemi-Amiri, A., \& McDonald, A. (2021). On lifetime extension of wind turbine drivetrains. In ASME 2021 40th International Conference on Ocean, Offshore and Arctic Engineering: Volume 9: Ocean Renewable Energy [V009T09A025] ASME. https://doi.org/10.1115/OMAE2021-62516 
failure is much smaller than that of the structural members, due to the higher loading frequencies. Furthermore, the inherently complex components contained within the drivetrain are subject to uncertainties associated with their manufacturing and operation [2].

Taking all the above into account, it appears that a methodology for determining the LTE of the drivetrain would be extremely useful and important. Since this has not been fully investigated previously, the objective of this paper is to investigate the LTE methodologies currently applied in the wind industry, as well as in other industries, to determine if they can be transferred to the methodology for the drivetrain.

The rest of this paper is structured as follows: Section II explains the methodology used to create this paper. Section III presents the existing methodologies and guidelines for LTE in various industries. Section IV describes the existing methodologies and guidelines for LTE in the wind industry. Further discussions on the findings from Sections III and IV are provided in Section V. Finally, Section VI sums up the conclusions and mentions the proposed future work.

\section{METHODOLOGY}

This paper's methodology is to review existing information available in the public domain, to learn and understand the methods currently used for LTE in both the wind industry, as well as in other industries. Some industries that have been in operation for many years prior to the development of the modern wind industry, already have tried and tested methods in place for determining LTE. Therefore, it is extremely useful and important to learn from other industries, to identify their transferable knowledge and the requirements for the wind industry. These are the points which will be discussed in Section V, which is the discussion section of the paper.

The industries investigated are Oil and Gas, Marine Vessels and the Wind Industry, along with components such as Electrical Machines, Mechanical Rotating Equipment and Bearings and Gears.

For each industry, a number of papers, articles, guidelines and standards related to LTE are reviewed. The assessment processes they used are then summarised and key take-away points identified. These key take-away points are items that have been identified as being applicable/transferable for use in determining the LTE process specifically for wind turbine drivetrains. A high level LTE methodology is then proposed by incorporating all the key points identified across the various industries, ensuring that previous gaps identified within existing guidelines are filled.

\section{III: EXISTING METHODOLOGIES/GUIDELINES IN VAR- IOUS INDUSTRIES a) Oil and Gas}

The Sintef Technology and Society [3] issued a report discussing the "Ageing and life extension for offshore facilities in general and for specific system". The report describes how a number of activities should be conducted in order to make sure that the technical, operational and organisational integrity of the asset is maintained throughout the LTE period. The main activities include updating procedures as per the latest regulations, collecting data and information on the asset to determine the current condition and how the level of integrity has been affected during the operational life, establish a LTE management plan which will detail how to maintain the asset during the additional operational lifetime, to keep the integrity level of the asset at an acceptable level.

Palkar et al. [4] explain certain guidelines that may be followed to assess the LTE and to maintain both the technical and operational integrity of the asset. They identify key aspects of ageing such as material degradation, obsolescence and organizational issues. They state that the main objective is to confirm whether the equipment is still fully functional and "fit-forpurpose". In order to do this it is important to have both past and present information. These tasks include, collection of data, breakdown of the system, screening, monitoring and testing, detailed analysis, evaluation of risks, outline of challenges and a LTE management plan. They concluded that the LTE process should not compromise on safety standards, that regular inspections with thorough documentation will keep the operators informed of the condition of the equipment and that communication is extremely important along with lessons learned and sharing knowledge. Finally they state that a software system is useful with analysing data and detecting changes.

Ratnayake [5] explains that the age of the equipment is not the only factor for ageing, it is also important to know how the equipment changes over time in its condition. They state that performing efficient inspections is a key component in LTE. Inspection methodologies are determined based upon the applications, as well as the input and output data.

Hudson [6] explains how important it is to develop an efficient asset integrity management (AIM) approach, which will not compromise on safety, integrity or the environment but achieve the required reliability and availability. He mentions that the approach needs to include AIM on all components and systems within the asset which affect the operation. The aim of the Asset Life Extension Study is to determine the location and reason of any deterioration, as well as developing a plan that details how the equipment's integrity can be maintained. The method proposed begins with the normal design life which is determined from the original design standards and best practices. Maintenance practices, inspection methods and history, operating practices and environmental conditions then aid in the determination 
of the impact of deterioration mechanisms. From these two assessments the assessed asset life can then be determined.

Sabry [7] explains in detail the LTE studies that were carried out by an ADNOC LNG team. Initially the asset was split into five sections, which were static equipment, safety critical equipment, rotating equipment, civil and structures and electrical and instrumentation. Then data was collected for the static equipment from a variety of systems such as risk based inspection, risk based assessment, focused integrity reviews, CMMS, root cause analysis, fitness for service exercise and major turn around reports. From here the inspection and failure history, degradation rates, probability of failure and fitness for service results were all analysed to determine if the static equipment would continue to operate until a set date.

Khan et al. [8] explains that there are many challenges with regards to maintaining the reliability and integrity of ageing equipment. In order to assess the LTE, many factors need to be taken into account such as erosion, corrosion, fatigue, obsolescence and change in standards, to name a few. The method they have described to assess suitability of the asset for LTE first begins with data and information, then criticality screening, analysis of failures and challenges, risk reducing measures, overall risk picture and finally LTE management. They describe that at each stage the asset must prove that they are fit-for-purpose and meet the As Low As Reasonably Practicable criteria.

\section{b) Marine Vessels and Floating Production Installa- tions}

Marine vessels operate in harsh and challenging environments so it is important that they are designed, constructed, maintained and operated according to strict standards, in order to operate safely and efficiently, as well as to protect the environment. Classification societies including Bureau Veritas (BV), Lloyds Register (LR) and the American Bureau of Shipping (ABS) issue regulations and standards that the marine vessel owner's must comply with in order for their vessels to be classed. Therefore, if they are to operate beyond their designed service life then reviews, surveys and structural analyses are required, in order to prove that they can continue to operate safely and efficiently.

ABS issued regulations for LTE of floating production installations (FPI) [9] in 2017. They state that the LTE process consists of three phases. The first being the investigation phase which involves data collection, engineering assessments and a baseline survey. The second phase is the determination phase, which involves reassessment and provision of conditions for LTE and the third phase is the implementation phase which is where the conditions are implemented.

\section{c) Electrical Machines}

Zhu et al. [10] discusses the use of condition monitoring of the stator insulation system via on-line partial discharge analysis
(PDA) systems. Insulation degradation of the stator can cause failures and reduce the life of the equipment. They looked at two case studies, a generator and a motor with degraded insulation, where both had an on-line PD testing system applied. They concluded that using on-line PD testing as a condition monitoring tool was extremely useful in determining the condition of the winding insulation of the stator. It gave the operators confidence in using the equipment and allowed LTE of the stator winding insulation in both motors and generators. By monitoring the deterioration of the insulation by a condition monitoring system, extends the service lifetime of the machine.

Fuchs et al. [11] explain in their book that temperature affects the insulation material in transformers and induction machines, by ageing the insulation which in turn affects the life. For magnetic devices, they explain the three phases that can be used to estimate the lifetime. The first being modelling of additional losses caused by harmonics of either voltage or current. The second phase is to establish the rises in temperature and the third phase is to determine the lifetime reduction as a percentage against the rated lifetime.

Huger et al. [12] investigated nonlinear models for dynamic electric and thermal machine behaviour. They simulated certain behaviour over the life of the machine, such as winding resistance and magnet temperatures. They concluded that the end windings were the most critical part of the winding insulation and the most likely component to fail was the bearings.

\section{d) Mechanical Rotating Equipment}

Sire et al. [13] discuss analytical modelling for LTE of ageing equipment. They state that it is important to select the most appropriate usage parameter for use in damage modelling. Damage parameters can come in many forms, such as crack length and structural wall thickness for structures. Loading can be defined as either cyclic or constant. Fatigue is an example of cyclic loading and creep or stress corrosion are examples of constant loading. Exposure time and/or loading cycles are examples of usage parameters. Upon selecting components for LTE, "materials data characterizing damage progression as a function of usage" should be taken from either testing in a laboratory or from a materials database. Validation of lifetime prediction model should be carried out by field experience. They concluded that suitable candidates for LTE should be the components that have extensive remaining life, which have been determined from reliable detection of damage. In order to carry out accurate predictions of the components life, multiple tools exist.

$\mathrm{Hu}$ et al. [14] investigated various methods of assessing the remaining useful life (RUL) of ageing mechanical equipment. They looked at three methods, the first being a physics based model, the second a data driven based model and the third a hybrid model of both methods. As the name suggests the physics based model is built upon engineering principles and/or physics 
dynamics. This model can easily adapt to new or unexpected operations. The data driven based model operates by comparing the "status assessments of the system during testing with all other learned occurrences", therefore historical data must be used to train the model. They concluded that modelling and assessment of RUL is becoming more important and that the decreasing RUL of all equipment is caused by physics performance degradation. It is difficult to see physics degradation, so RUL evaluation is recommended for determining the degradation process, by using physics performance data that is available. Typically the two processes that are used in the RUL evaluation are, "the hidden degradation process and observation of measurable processes". The observation process and data are used to determine the degradation process, as well as converting the degradation state into a probability density distribution. This then produces the HMM mechanism and Bayesian recursive estimation, which is conveyed in a state space model. Modelling of both the system and observation equation of the state space model is best achieved by using a mixture of "the physics model based method and historical data fitting for parameter initiation a data driven hybrid method."

\section{e) Bearings and Gears}

Loutas et al. [15] investigated using a data-driven approach based on E-Support Vector Regression to estimate the RUL of rolling element bearings. They concluded that the methodology that they proposed can be used for any task for predicting probabilistic RUL.

Singleton et al. [16] investigated using the extended Kalman filtering for determining the RUL of bearings. It is difficult to predict the RUL of bearings because accurate physical degradation models are lacking. They propose using a data-driven methodology, which will use both time and time-frequency domain features to monitor any bearing faults. After the features are extracted, an analytical function is developed and then used to learn the extended Kalman filter parameters. This is then used on test data to predict faults under different operating conditions.

An article has been written in the Wind System magazine regarding improving the service life of rotating equipment [17]. They specifically look at proper selection and installation of bearings along with maintenance practices, condition monitoring and predictive maintenance. There are a number of reasons that can cause high stress values which in turn cause fatigue in the bearings, they are friction, heat, heavy moment loads, reduced material strength caused by water contamination, corrosion and stray electrical currents. One way to prevent this is by using specific surface treatments. Other solutions they recommend are, proper lubrication management, condition monitoring and a PdM program.

\section{EXISTING METHODOLOGIES/GUIDELINES IN WIND INDUSTRY}

Bureau Veritas issued the "Guidelines for Wind Turbines Lifetime Extension" [18] in 2017, which recommend carrying out inspections on the components of the turbine to determine the quantitative LTE. For the structural components which include the tower, blades and main shaft, LTE calculations are also required to be carried out. With regards to the drivetrain, the gearbox, shrink disk, torque arms, rotor locking system, brake disc and caliper, high speed coupling, hoses and oil ancillaries and the generator mount are listed along with the inspection requirements.

DNV-GL issued both the "Lifetime Extension of Wind Turbines (DNVGL-ST-0262)" [19] and the "Certification of Lifetime Extension of Wind Turbines (DNVGL-SE-0263)" [20], in 2016. Document DNVGL-ST-0262 recommends four methods for determining if the wind turbine is suitable for LTE. The first method is called the lifetime extension inspection (LEI). For this method a visual inspection is carried out on all load-transferring or safety-relevant components. Maintenance and inspection reports are reviewed, along with some simple tests and consideration of both SCADA data and type related field experience. The next three methods which are the Simplified, Detailed and Probabilistic Approach, are all carried out to determine proof of strength and stability. They each consist of an analytical and practical part. The analytical part involves new and/or additional calculations to assess the LTE of the wind turbine. The calculations should take into consideration the location of the wind turbine, including the site-specific installation, local conditions and the field experience related to the type of turbine. The practical part involves wind turbine inspections, which should include all components that are load transferring and the control and protection system. In addition to the inspections, the maintenance/operational history and field experience related to the type of turbine, should also be taken into account. With regards to the drivetrain, it has been broken down into eleven components, including, the hub, main shaft, coupling, main shaft bearings, gearbox, torque support, high speed shaft, generator, cooling system/circuit, bolted connection and protective covers. Each component has its individual test that should be conducted. Document DNVGL-SE-0263 explains the main deliverables including a report, statement of compliance and/or certificate, obtained from carrying out one of the methods for LTE described in document DNVGL-ST-0262. The document confirms that the possible LTE is determined from load calculations and inspections. Each wind turbine should be inspected and the scope of the inspection will depend on the results obtained from the analytical part. Results obtained from both the analytical and practical parts will determine whether the wind turbine is suitable for LTE. TUV Nord [21] (2017) recommend the use of both these guidelines for assessing the LTE of wind turbines.

MegaVind issued a report called "Strategy for Extending the 
Useful Lifetime of a Wind Turbine" [22] in 2016. They have described four different scenarios based upon the amount of data available, from no design basis and operational measurements being available (Scenario 1), to having access to a full range of information including the design basis, the history of load measurements, wind speed details and condition monitoring measurements (Scenario 4). The accuracy of the LTE assessment increases from Scenario 1 through to Scenario 4. This report also mentions that it is important to have information on the environmental conditions that the wind turbine has been operating in, in order to more accurately determine the remaining useful life (RUL) of the turbine. They also discuss conducting a component-by-component analysis, which explains the requirements for the LTE calculations, the various failure modes and ways to improve both the inspection and condition monitoring. The nacelle section is split into the shaft and main bearing, frame, electrical components and yaw systems.

BWE discusses the "Basic Principles for Performing an Assessment and Verification of the Lifetime Extension of Onshore Wind Energy Converters (BPW)" [23]. They state that the integrity of the tower, foundations and load-transferring components and functionality of the safety, control and brake systems all need to be assessed in order to determine the LTE. They also state that in order to determine the LTE of a wind turbine, then both an analytical part and practical part need to be carried out. Where the analytical part is determined using the available documentation and practical part involves an inspection.

Ziegler et al. [24] researched LTE for onshore wind turbines across various countries in Europe by carrying out a thorough literature review and interviewing a number of operators. They looked at conducting load simulations along with technical assessments. They concluded that the analytical part of the assessment is conducted by using both structural models and actual site conditions. Obtaining the actual site conditions at present is costly, so this needs to be reviewed further to establish a more cost-effective method. The practical part of the assessment determines the current condition but doesn't determine the structural safety level.

Rubert et al. [25] explains how the approach for LTE can be split into two. The first being data evaluation using SCADA data, maintenance reports, survey reports, wind history and CMS. The second is inspections of the drivetrain, non-destructive inspection (NDI) of any connections that are bolted and welded, corrosion areas, blades and electrical components.

Perez et al. [26] discuss a methodology for damage detection in offshore platforms. They use the Submatrices Damage Method to establish damage indicators in terms of stiffness degradation. It works by comparing the structural stiffness of the baseline conditions with the damaged conditions. To detect the location of the damage, limited modal information is used. They conclude that the proposed methodology identifies and locates the damage in terms of stiffness degradation. Both the Baruch and Bar-Itzhack and the Berman and Nagy methodologies were used and both enabled the Submatrices Damage Method to accurately locate the damage.

Kazemi Amiri et al. [27] developed a methodology for determining the LTE of onshore wind turbine towers. The tower is assumed to be the key structural component. They used a joint aeroelastic-finite element analysis, ensuring that they took into consideration the wind direction, operational history and stress magnification present around the door of the tower.

Rubert et al. [28] discuss the use of using data collected from structural health monitoring (SHM) to establish a LTE strategy. They explain that data analysis, inspections, aero-elastic simulations and data from SHM systems are all methods that can be used to determine the LTE of the turbine. The first three methods (i.e. data analysis, inspections and aero-elastic simulations) can be lacking in information or costly, which can be avoided by using data from SHM. They concluded that determining the LTE of a turbine depends highly on its location and thus the site specific conditions and that it is extremely important to establish an appropriate strategy for LTE.

An article written in the Wind Systems magazine [29] discuss extending the lifetime of wind turbines. They mention that the assessment consists of an analytical and practical part. All load bearing components, safety devices, turbine control systems and braking systems are analysed. They discuss how it is important to determine the actual loads and stresses that the wind turbine has been exposed to and this is done by computer simulations. The simulations must reproduce the design conditions after type testing and the actual operating conditions. They concluded that in general the turbines experience lower loads due to the wind conditions but the rotor blade bolts typically reach their design limit faster.

Natarajan et al. [30] identifies bolts, blade erosion and the effective repair of faults as the main inspection points, from which the results can determine the LTE. They confirm that the standards issued focus on fatigue limit states. They are proposing to use 10-minute average SCADA data and aeroelastic design basis to estimate the shaft torsional load, using the collage method and Tikhonov method. Once the shaft torsional load has been determined the fatigue damage equivalent loads (DEL) can then be calculated on all major structural components such as the blades and tower. They mention that the DEL values calculated from measurements provide a more accurate estimate of fatigue life, which in turn will be more efficient for estimating the LTE of older turbines. They also conducted interviews with owners and they confirmed that critical components include the tower and drivetrain, which is classed as the most critical component.

Attempts have been made to particularly study the wind turbine's drivetrain damage and its LTE potentials. Girsang et al. [31] discusses the use of a modelling tool that can model the impacts of electrical transients, wind turbulence and shear on the wind turbine's drivetrain. They recommend using the FAST CAE 
tool along with Simscape to model the drivetrain to look at ways of extending the life of the gearbox by testing advanced control schemes.

Dvork [32] wrote a paper discussing how turbulent winds effect the wind turbine's drivetrains. They experience a wide range of dynamic loads which may reduce the predicted life of the components in the drivetrain. Transient torque reversals cause strong oscillations, so need to be taken into account, as they affect the bearings and gearings in the gearbox.

Keller at al. [33] discusses combining physics-based and data-driven models to estimate the RUL of the drivetrain. Improving the reliability will assist in LTE. In order to improve drivetrain reliability, opportunities such as new technologies, to modifying Operating and Maintenance procedures can be considered.

\section{V: FURTHER DISCUSSIONS AND REQUIREMENTS a) Oil and Gas}

The oil and gas industry has been around for decades prior to the development and installation of modern wind farms, particularly offshore wind farms. Therefore, they have some established LTE methods which may or may not be suitable for use on wind turbines.

Although the oil and gas industry and wind industry have large differences, the main one being that one extracts and transports non-renewable fossil fuels from under the ground, whilst the other converts natural renewable sources from above the ground i.e. the wind, to electrical power, there are also some similarities. One similarity is that the assets in both industries are subjected to very similar environmental conditions, such as the harsh offshore environment, which in turn means similar maintenance and repair costs. Another similarity is that both assets consist of structural, mechanical and electrical components.

A typical oil and gas asset consists of a jacket structure, topside equipment such as a christmas tree, pumps, valves, electrical equipment etc., risers and pipelines. Therefore the LTE process should cover all of these components.

Information from references [3], [4], [5], [6], [7] and [8] have been collected and summarized in Figure 1.

The methodology begins by breaking down the system into components, then collecting both past and present data to determine the condition of the equipment/component. The more data collected the more accurate the final result will be. Screening or thorough inspections are then carried out. Failures are analysed, risks determined, with the final deliverable being a Lifetime Extension Management Plan.

Key Take-Away Points The main take-away points are:

1. Break the system down into components.
2. Collect past and present data for all components. The more data collected the more accurate the prediction.

3. A physics-based approach for determining RUL is preferred.

4. Analyse all failures modes.

5. Evaluate risks and challenges.

6. Establish a Lifetime Extension Management Plan.

\section{b) Marine Vessels and Floating Production Installa- tions}

Marine vessels and floating production installations house a large number of people, often in challenging offshore environments, so it is important that they meet strict standards with regards to design, construction, maintenance and operation. Therefore, they are classed and must follow the standards with regards to LTE.

The methodology they use for LTE consist of three phases, which are Investigation, Determination and Implementation.

Both the baseline survey, which is part of the Investigation Phase and reassessment which is part of the Determination Phase, are typically applied to the structures (hull and topside), mooring system, stability and machinery and systems. Depending on the component/system, strength and/or fatigue and/or stability analysis will be carried out. Environmental conditions are also an important factor to consider. Surveys are then conducted to confirm the condition of the vessel.

Key Take-Away Points The main take-away points are:

1. Break the system down.

2. Consider the environmental conditions.

3. Implement three phases, investigation, determination and implementation.

4. Conduct thorough surveys.

5. Carry out the most appropriate analysis for each component/system.

6. Implement the conditions determined from the first two phases.

\section{c) Electrical Machines}

Electrical machines typically refer to motors and generators. Generators are present in all wind turbine drivetrains, so it is useful to establish what methods are currently in place for their LTE.

References [10], [11] and [12] all indicate that one of the main factors affecting the lifetime of electrical machines is degradation of the insulation, which is caused by high temperatures. Therefore, the methods which have been proposed, to determine the condition of the insulation are by either modelling of the losses or machine behaviour, or by monitoring the deterioration by a condition monitoring system, specifically an on-line partial discharge system. 



FIGURE 1. Summary of Lifetime Extension Process in Oil and Gas Industry.

Key Take-Away Points The main take-away points are:

1. Condition monitoring such as on-line partial discharge testing is useful for determining the condition of the insulation.

2. Modelling of the machine's behaviour or additional losses can assist with determining the RUL.

3. Bearings are the components that are most likely to fail.

\section{d) Mechanical Rotating Equipment}

Again the wind turbine's drivetrain consists of rotating mechanical equipment. References [13] and [14] investigated the best modelling methods to use and the most appropriate parameters, respectively. The methods included physics-based, databased and a hybrid model.

Key Take-Away Points The main take-away points are:

1. Determine which components will directly affect the machines LTE.

2. Select the best candidates for use in modelling the damage.

3. Use of physics-based method along with historical data for modelling the system gives the best results.

4. The model established to predict LTE should be validated via field experience.

\section{e) Bearings and Gears}

Along with a generator, bearings are present in all drivetrains, whereas gearboxes are present in some but there is a move towards low-speed generators, thus eliminating the need of a gearbox. One of the main reasons for eliminating the gearbox from the drivetrain is the fact that the gearbox has a high number of failures, which increases costs.
Bearing failure is also quite a common occurrence and references [15] and [16] investigated modelling techniques to determine the RUL of bearings. Data-driven methods were used in both cases but in the first case an E-support Vector Regression is used, whereas Kalman filtering is used in the second case.

Key Take-Away Points The main take-away points are:

1. Condition monitoring is important for extracting data for the bearings.

2. Data-based methods are recommended for predicting the RUL of the bearings.

\section{f) Wind Turbines}

The guidelines issued by both DNV-GL and Bureau Veritas give an overview of the LTE process for wind turbines as a whole. They explain the different approaches that can be carried out based upon the amount of data available.

Key Take-Away Points The main take-away points are:

1. Simplified approach is carried out when the original design documentation is not available.

2. Detailed approach is carried out when the original design documentation is available and uses a deterministic approach.

3. Probabilistic approach uses a stochastic approach to calculate the structural integrity.

4. Practical part for each method is similar no matter which approach is used.

5. Visual inspection is required to be carried out on all loadtransferring, safety and the control and protection system 
components.

6. Important to consider the location of the turbine, the sitespecific installation, local conditions and field experience for each turbine when carrying out the analysis.

7. Physics-based and data-based models can be used to determine the RUL of the drivetrain.

\section{g) Summary}

The LTE process can be split into a number of stages, with the first stage of the process being data collection. A common conclusion is that the more data available and collected the more accurate the final results will be. The data typically comes from SCADA data, condition monitoring system, design drawings, manufacturing drawings, installation reports, maintenance reports, failure records, operational history etc.

The next stage is to determine the assessment type. The common types of assessment to determine LTE, that appears to be used across many industries are analytical and/or practical assessments, with the use of both providing a more accurate outcome. Analytical assessments can cover modelling, simulations, calculations etc., whereas practical assessments refer to surveys and inspections of the assets.

The main stage is then conducting the assessments based on the methods determined from the equipment/system/plant type and data available. Depending on the industry and the amount of data collected, the depth of each type of assessment will vary. In this stage it is important to consider environmental conditions, as well as the conditions that the components have been operating in throughout their lifetime.

The results from the assessments will then determine whether the operational life of the equipment/plant/system can be extended and by how long. It will also determine whether any additional operating and maintenance practices will need to be implemented and the frequency of them.

\section{h) Proposed Lifetime Extension for Wind Turbine Driv- etrains}

Current standards and guidelines that have been issued, set out an overview of recommended LTE assessments for wind turbines as a whole and this has been summarised in Section IV. In addition to the guidelines/standards, a large amount of research has been carried out on LTE of wind turbine structures, in which some have also been discussed in Section IV but there appears to be a gap where LTE specifically of wind turbine drivetrains is concerned. Therefore, after reviewing a large number of sources, the following lifetime assessment process has been proposed for the LTE process for drivetrains and summarized in Figure 2.

Stage 1: Data Collection It was mentioned earlier in the paper that the more data available then the more accurate the results would be. With this in mind the data that would be required include Design Drawings and Calculations, Manufacturing Documents/As-built drawings, Installation Documents, OEM Manuals, Maintenance Logs, Failure Reports and Details of Repair, Operational Conditions, Environmental Conditions, Temperature Measurements (Equipment), Vibration Measurements (Equipment), Number of Wind Turbines in the Wind Farm and Layout of the Wind Farm.

Stage 2: System Breakdown The drivetrain system would then be separated into individual components/groups including Shaft (Main and High Speed), Bearings, Gearbox, Generator, Power Converter, Housings/Protective Covers, Bed Plates/Mounts, Bolted Connections, Brake Disks, Torque Arms/Support, Rotor Locking System, Coupling, Shrink Disks, Hoses and Oil Ancillaries and the Cooling System.

Stage 3: Assessment Type The recommended type of assessment consists of Analytical/Modelling/Calculations and Practical/Surveys/Inspections.

Stage 4a: Analytical Assessment The recommended analytical assessment will consist of but not be limited to the following:

1. Calculation of loads that each component has been subjected to throughout its life to date, based upon the operational and environmental conditions.

2. Model each component and the system as a whole.

3. Determine the damage/degradation for each component using both the loads calculated and modelling simulations.

The LTE assessment is typically only carried out towards the end of the asset's operational design life, which means that a vast amount of SCADA and/or condition monitoring data, such as items 7, 8 and 9 in Stage 1, would need to be stored which is not practical. Therefore, it would be proposed that a smaller analysis is carried out each year just to determine the damage equivalent loads (if any) of the components from the previous year and only this information be stored. This would also be beneficial as any unexpected results could then be addressed to avoid shortening the components operational design life.

Stage 4b: Practical Assessment The recommended practical assessment will consist of but not be limited to the following:

1. Visual inspection of the components including the shaft, coupling, bolted connections, cooling system, protective covers, safety system etc. 


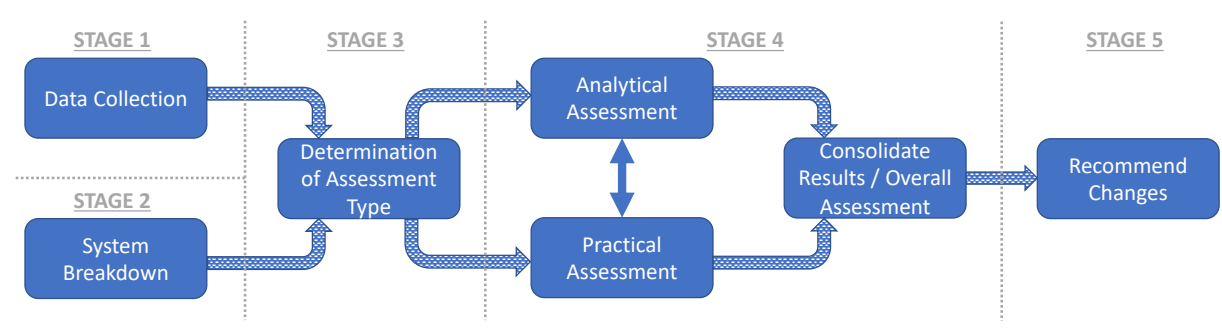

FIGURE 2. Flowchart of Proposed Methodology for LTE of Wind Turbine Drivetrains.

2. Alignment checks of the system including gearbox and generator.

3. Material thickness measurements on components including the mechanical brake, sliding contacts, gearbox etc.

4. Confirm oil checks have been conducted as part of the maintenance procedures.

5. Check the temperature and vibration measurements correspond with the SCADA data.

The results from the survey/inspection can then be compared with the results calculated in the analytical assessment. If there is a vast difference in which the condition of the components are worse than expected, then the model can be updated accordingly.

Stage 4c: Overall Assessment Once both the analytical and practical assessments have been completed the RUL for each component can then be determined. It is important to be able to determine the LTE of all individual wind turbines in a wind farm. In some instances it may not be possible or practical to analyse and inspect each individual wind turbine, therefore a process to assess a certain number of turbines and then use those results to predict the other turbines is extremely beneficial and will be determined and investigated. Inspections will be one method that will be used to help with uncertainties.

Stage 5: Recommended Changes Once it has been decided that LTE is applicable, then any conditions that would need to be implemented such as additional Operational and Maintenance Procedures to maintain the expected LTE should be noted.

\section{VI: CONCLUSION AND FUTURE WORK}

The objective of this paper was to research and review the LTE processes currently used in both the wind industry, as well as in other industries. This was to determine if the established processes used in other industries could be applicable to the wind industry. It can be concluded that it appears that knowledge of the LTE processes used in industries such as oil and gas, electrical machines, bearings, marine vessels etc. can be transferred to the wind industry.

Following on from the work carried out in this paper, the next stage is to establish and implement a methodology and the necessary tools, for determining the LTE of wind turbine drivetrains.

\section{ACKNOWLEDGMENT}

Thanks go to the EPSRC for supporting this work through the EPSRC Centre for Doctoral Training in Wind and Marine Energy Systems and Structures (Grant Number EP/S023801/1).

\section{REFERENCES}

[1] WindEurope, 2019. Wind energy in Europe in 2019 - trends and statistics. https://windeurope.org/dataand-analysis/product/wind-energy-ineurope-in-2019-trends-and-statistics/. [Online; accessed 22-Dec.-2020].

[2] Guo, Y., Bergua, R., van Dam, J., Jove, J., and Campbell, J., 2014. "Improving wind turbine drivetrain reliability using a combined experimental, computational, and analytical approach". In International Design Engineering Technical Conferences and Computers and Information in Engineering Conference, Vol. 46407, American Society of Mechanical Engineers, p. V007T05A004.

[3] Hokstad, P., Håbrekke, S., Johnsen, R., and Sangesland, S., 2010. "Ageing and life extension for offshore facilities in general and for specific systems". SINTEF Report for the Petroleum Safety Authority Norway.

[4] Palkar, S., and Markeset, T., 2011. "Extending the service life span of ageing oil and gas offshore production facilities". In IFIP International Conference on Advances in Production Management Systems, Springer, pp. 213-221.

[5] Ratnayake, R. C., 2012. "Challenges in inspection planning for maintenance of static mechanical equipment on ageing oil and gas production plants: The state of the art". In International Conference on Offshore Mechanics and Arctic Engineering, Vol. 44939, American Society of Mechanical Engineers, pp. 91-103. 
[6] Hudson, B., $2015 . \quad$ Offshore Installation Life Assessment and Extension. https://www. maintenanceandengineering.com/2015/ 01/01/offshore-installation-lifeassessment-and-extension/, January.

[7] Sabry, H., 2018. "Aging lng static equipment life extension - a case study". In Abu Dhabi International Petroleum Exhibition \& Conference, Society of Petroleum Engineers.

[8] Khan, R., Mad, A. B., Osman, K., and Abd Aziz, M. A., 2019. "Maintenance management of aging oil and gas facilities". In Maintenance Management. IntechOpen.

[9] ABS. Life Extension Methodology for Floating Production Installations, latest ed. ABS, USA.

[10] Zhu, H., Green, V., and Huynh, D., 2002. "Lifetime extension experience on rotating machine insulation using online pd testing". In Conference Record of the the 2002 IEEE International Symposium on Electrical Insulation (Cat. No. 02CH37316), IEEE, pp. 561-564.

[11] Fuchs, E., and Masoum, M., 2008. "Chapter 6 - lifetime reduction of transformers and induction machines". In Power Quality in Power Systems and Electrical Machines, Academic Press, pp. 227-260.

[12] Huger, D., and Gerling, D., 2014. "An advanced lifetime prediction method for permanent magnet synchronous machines". In 2014 International Conference on Electrical Machines (ICEM), IEEE, pp. 686-691.

[13] Sire, R., and Hopkins, S., 1997. "Analytical modeling for life extension of aging equipment". International journal of fatigue, 19(93), pp. 261-266.

[14] Hu, Y., Liu, S., Lu, H., and Zhang, H., 2019. "Remaining useful life model and assessment of mechanical products: a brief review and a note on the state space model method". Chinese Journal of Mechanical Engineering, 32(1), p. 15.

[15] Loutas, T. H., Roulias, D., and Georgoulas, G., 2013. "Remaining useful life estimation in rolling bearings utilizing data-driven probabilistic e-support vectors regression". IEEE Transactions on Reliability, 62(4), pp. 821-832.

[16] Singleton, R. K., Strangas, E. G., and Aviyente, S., 2014. "Extended kalman filtering for remaining-useful-life estimation of bearings". IEEE Transactions on Industrial Electronics, 62(3), pp. 1781-1790.

[17] Mag, W. S., 2020. Improving the Service Life of Rotating Equipment. https://www.windsystemsmag. com/improving-the-service-life-ofrotating-equipment/, February.

[18] Bureau Veritas, 2017. Guidelines for Wind Turbines Lifetime Extension, latest ed. Bureau Veritas, France.

[19] DNV-GL, 2016. DNVGL-ST-0262 - Lifetime extension of wind turbines, latest ed. DNV-GL, Norway.

[20] DNV-GL, 2016. DNVGL-ST-0263 - Certification of lifetime extension of wind turbines, latest ed. DNV-GL, Norway.

[21] Nord, T., 2017. Certification of Lifetime Exten- sion. www.tuev-nord.de/en/company/energy/ renewables/wind-energy/, May.

[22] Megavind. Strategy for Extending the Useful Lifetime of a Wind Turbine, latest ed. Megavind, Denmark.

[23] BWE Grundsätze. Basic Principles for Performing an Assessment and Verification of the Lifetime Extension of Onshore Wind Energy Converters (BPW), latest ed. BWE Grundsätze, Germany.

[24] Ziegler, L., Gonzalez, E., Rubert, T., Smolka, U., and Melero, J. J., 2018. "Lifetime extension of onshore wind turbines: A review covering germany, spain, denmark, and the uk". Renewable and Sustainable Energy Reviews, 82, pp. 1261-1271.

[25] Rubert, T., Ziegler, L., Gonzalez, E., McMillan, D., Smolka, U., and Melero, J. J., 2017. The UK's state-ofthe-art of lifetime extension of onshore wind turbines. https://events.renewableuk.com/images / documents/OAM17/A3-Tim-Rubert.pdf.

[26] Pérez, J. E. R., Rodríguez, R., and Vázquez-Hernández, A. O., 2017. "Damage detection in offshore jacket platforms with limited modal information using the damage submatrices method". Marine Structures, 55, pp. 78-103.

[27] Amiri, A. K., Kazacoks, R., McMillan, D., Feuchtwang, J., and Leithead, W., 2019. "Farm-wide assessment of wind turbine lifetime extension using detailed tower model and actual operational history". In Journal of Physics: Conference Series, Vol. 1222, IOP Publishing, p. 012034.

[28] Rubert, T., Zorzi, G., Fusiek, G., Niewczas, P., McMillan, D., McAlorum, J., and Perry, M., 2019. "Wind turbine lifetime extension decision-making based on structural health monitoring". Renewable Energy, 143, pp. 611-621.

[29] Mag, W. S., 2019. Extending the Lifetime of Wind Turbines. https://www.windsystemsmag. com/extending-the-lifetime-of-windturbines/, October.

[30] Natarajan, A., Dimitrov, N. K., Peter, D. R. W., Bergami, L., Madsen, J., Olesen, N., Krogh, T., Nielsen, J., Sørensen, J. D., Pedersen, M., et al., 2020. "Demonstration of requirements for life extension of wind turbines beyond their design life".

[31] Girsang, I. P., Dhupia, J. S., Muljadi, E., Singh, M., and Pao, L. Y., 2014. "Gearbox and drivetrain models to study dynamic effects of modern wind turbines". IEEE Transactions on Industry Applications, 50(6), pp. 3777-3786.

[32] Dvorak, P., 2015. How turbulent winds abuse wind turbine drivetrains. https://www. windpowerengineering.com/how-turbulentwind-abuse-wind-turbine-drivetrains/.

[33] Keller, J., Sheng, S., Cotrell, J., and Greco, A., 2016. "Wind turbine drivetrain reliability collaborative workshop: A recap". 